\title{
The paramount parameter: arterial oxygen tension versus arterial oxygen saturation as target in trials on oxygenation in intensive care
}

\author{
Olav Lilleholt Schjørring ${ }^{1,2^{*}}$ (D) and Bodil Steen Rasmussen ${ }^{1,2}$ (D)
}

Keywords: Oxygen inhalation therapy, Hyperoxia, Hypoxia, Intensive care units, Respiratory insufficiency, Critical illness

\begin{abstract}
Main text
Oxygenation targets in critically ill patients admitted to the intensive care unit (ICU), in particular in patients with acute hypoxaemic respiratory failure, are still a matter of debate. There is mounting evidence for potential harm through hyperoxia [1-3]. Nevertheless, the optimal oxygenation targets, which minimise hyperoxia while maintaining sufficient oxygenation to avoid harm through hypoxia, remain unclear. Therefore, larger randomised clinical trials on the subject are needed. Several observational studies [4] as well as interventional before-and-after trials $[1,5]$ and three small randomised controlled trials $[2,3,6]$ have added valuable, although not definitive, evidence to the field. Arterial oxygen saturation $\left(\mathrm{SaO}_{2}\right)$ or pulse oximetry $\left(\mathrm{SpO}_{2}\right)$ has been the primary parameter defining the target range in most of the interventional studies conducted. We would like to dispute this preference of $\mathrm{SaO}_{2}$ and $\mathrm{SpO}_{2}$ over arterial oxygen tension $\left(\mathrm{PaO}_{2}\right)$ as the target parameter. Hence, this proposition for debate.

The general hypothesis of the studies on oxygen use in the ICU is that the dangers of oxygen toxicity are underestimated, and that the negative impact of hyperoxia is significant, even when compared to the risks of hypoxia following conservative oxygenation strategies $[1,2,5,6]$. Hence, studies proposing more conservative oxygenation targets have been conducted primarily in the effort to
\end{abstract}

\footnotetext{
* Correspondence: o.schjoerring@rn.dk

${ }^{1}$ Department of Anaesthesia and Intensive Care Medicine, Aalborg University Hospital, Hobrovej 18-22, 9000 Aalborg, Denmark

2Department of Clinical Medicine, Aalborg University, Søndre Skovvej 15, 9000 Aalborg, Denmark
}

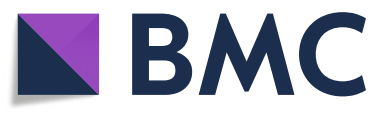

(c) The Author(s). 2018 Open Access This article is distributed under the terms of the Creative Commons Attribution 4.0 International License (http://creativecommons.org/licenses/by/4.0/), which permits unrestricted use, distribution, and

reproduction in any medium, provided you give appropriate credit to the original author(s) and the source, provide a link to the Creative Commons license, and indicate if changes were made. The Creative Commons Public Domain Dedication waiver (http://creativecommons.org/publicdomain/zero/1.0/) applies to the data made available in this article, unless otherwise stated. avoid hyperoxia. The parameters $\mathrm{PaO}_{2}$ and $\mathrm{SaO}_{2}$ are linked as visualised in the oxygen dissociation curve [7]. The interval of $\mathrm{PaO}_{2}$ in ICU patients spans upwards from approximately $7.3 \mathrm{kPa}(55 \mathrm{mmHg})$ [8-10]. In this area, the oxygen dissociation curve is rather flat [7] and covers only a small range of $\mathrm{SaO}_{2}$ values. The $\mathrm{SaO}_{2}$ range becomes even narrower with hyperoxaemic levels of $\mathrm{PaO}_{2}$ depending on its definition, which varies from over $13.3 \mathrm{kPa}(100 \mathrm{mmHg})$ to over $64.9 \mathrm{kPa}(487 \mathrm{mmHg})$ [4], while the corresponding $\mathrm{SaO}_{2}$ encompasses only four numeric values from $97 \%$ to $100 \%$. This limits the control of hyperoxaemia if $\mathrm{SaO}_{2}$ is used as the target parameter of oxygenation. Furthermore, when $\mathrm{SaO}_{2}$ defines the oxygenation target in clinical trials, the narrow $\mathrm{SaO}_{2}$ spectrum will likely result in a larger risk of an overlap of $\mathrm{PaO}_{2}$ or $\mathrm{SaO}_{2}$ between the conventional and interventional study groups.

One could argue that the use of $\mathrm{SaO}_{2}$ over $\mathrm{PaO}_{2}$ offers the possibility to use the non-invasive measurement of oxygenation, $\mathrm{SpO}_{2}$. The correlation between $\mathrm{SaO}_{2}$ and $\mathrm{SpO}_{2}$ is generally high which makes $\mathrm{SpO}_{2}$ invaluable in the continuous monitoring and titration of oxygen supplementation in the ICU [11]. Nevertheless, $\mathrm{SpO}_{2}$ is unreliable as a measure of arterial oxygenation in patients with sepsis [12], in patients with use of vasopressors [13], in patients with high or low body temperature [11], and in patients with hypoxaemia $[12,13]$. Therefore, $\mathrm{SpO}_{2}$ cannot be used in the ICU without intermittent measurements of $\mathrm{SaO}_{2}$ for comparison as remarkable differences above 4.4 percentage points [11] may occur. Furthermore, $\mathrm{SpO}_{2}$ has been shown inadequate in identifying and in quantifying hyperoxaemia defined as $\mathrm{PaO}_{2}$ above $16.7 \mathrm{kPa}(125 \mathrm{mmHg})$ at $\mathrm{SpO}_{2}$ levels 
above 96\% [14]. Thus, targeting normoxaemic oxygenation levels in the upper part of the normal reference interval by using $\mathrm{SpO}_{2}$ would inarguably lead to episodes of definitive hyperoxaemia. Moreover, at the steep slope of the oxygen dissociation curve [7], where the differentiation in $\mathrm{SaO}_{2}$ is the highest, $\mathrm{SpO}_{2}$ is also inadequate in correctly identifying the oxygenation level in the ICU as $\mathrm{SpO}_{2}$ above $94 \%$ is necessary to avoid a risk of having $\mathrm{SaO}_{2}$ below 90\% [13]. This fact further narrows the spectrum of differentiation when using $\mathrm{SpO}_{2}$.

An argument for using $\mathrm{SaO}_{2}$ over $\mathrm{PaO}_{2}$ is that under normal, healthy conditions more than $98 \%$ of the transported oxygen is bound to haemoglobin [7]. Therefore, $\mathrm{SaO}_{2}$ in combination with the haematocrit or haemoglobin level represents the most direct parameter for expressing the amounts of oxygen actually carried in the arterial blood whereas $\mathrm{PaO}_{2}$ is only a secondarily derived parameter. However, the oxygen dissociation curve [7] shows that $\mathrm{SaO}_{2}$ and $\mathrm{PaO}_{2}$ are mutually dependent, and so this point remains essentially theoretical. Additionally, with increasing hyperoxaemia $\mathrm{SaO}_{2}$ loses its value due to the rigid ceiling of $\mathrm{SaO}_{2}$ at $100 \%$. Furthermore, since the formation of reactive oxygen species is closely linked to the free amounts of oxygen [15] and since the reactive oxygen species contribute importantly to the detrimental effects of hyperoxia [15], $\mathrm{PaO}_{2}$ is probably the parameter with the tightest relationship to the toxic properties of oxygen. As these toxic properties are what trials on the subject strive to minimise, one could claim that this connection is just as important as the link between $\mathrm{SaO}_{2}$ and the total oxygen content of the blood.

In clinical practice, both $\mathrm{SaO}_{2}$ and $\mathrm{PaO}_{2}$ are commonly used to guide oxygen therapy, particularly in the ICU setting, as the majority of acute critically ill ICU patients require arterial cannulation for haemodynamic monitoring. For evaluating arterial oxygenation, a recent survey of northern European ICU physicians has shown that $\mathrm{PaO}_{2}$ was preferred to $\mathrm{SaO}_{2}$ [16].

In summary, to define the oxygenation target levels precisely, to reduce the risk of unwanted hyperoxaemia, and to minimise overlap between conventional and interventional groups, in clinical trials of higher versus lower oxygenation targets in the ICU population, $\mathrm{PaO}_{2}$ is in our opinion the superior target parameter as compared to $\mathrm{SaO}_{2}$. This is also reflected in clinicians' self-reported preferences. Therefore, we advocate the use of $\mathrm{PaO}_{2}$ as the primary target parameter of arterial oxygenation in future clinical trials that aim to establish the evidence of how to use medical oxygen in patients admitted to the ICU.

\section{Abbreviations}

HOT-ICU: Handling Oxygenation Targets in the Intensive Care Unit; ICU: Intensive care unit; $\mathrm{PaO}_{2}$ : Arterial oxygen tension; $\mathrm{SaO}_{2}$ : Arterial oxygen saturation; $\mathrm{SpO}_{2}$ : Pulse oximetry
Acknowledgements

Not applicable.

Funding

OLS' PhD project is funded by a grant from Innovation Fund Denmark.

Availability of data and materials

Not applicable.

\section{Authors' contributions}

BSR conceived the idea for the editorial. OLS drafted the primary manuscript OLS and BSR revised the manuscript together. Both authors have read and approved the final manuscript.

Ethics approval and consent to participate

Not applicable.

\section{Consent for publication}

Not applicable.

\section{Competing interests}

Both authors are involved in an ongoing investigator-initiated randomised trial targeting oxygenation in acutely ill patients in the ICU, the Handling Oxygenation Targets in the Intensive Care Unit (HOT-ICU) trial (ClinicalTrials.gov NCT03174002), OLS as coordinating investigator and BSR as sponsor and primary investigator.

\section{Publisher's Note}

Springer Nature remains neutral with regard to jurisdictional claims in published maps and institutional affiliations.

Received: 4 October 2018 Accepted: 6 November 2018

Published online: 22 November 2018

References

1. Helmerhorst HJ, Schultz MJ, van der Voort PH, Bosman RJ, Juffermans NP, de Wilde RB, et al. Effectiveness and clinical outcomes of a two-step implementation of conservative oxygenation targets in critically ill patients: a before and after trial. Crit Care Med. 2016;44(3):554-63.

2. Girardis M, Busani S, Damiani E, Donati A, Rinaldi L, Marudi A, et al. Effect of conservative vs conventional oxygen therapy on mortality among patients in an intensive care unit: the Oxygen-ICU Randomized Clinical Trial. JAMA. 2016; 15:1583-9.

3. Asfar P, Schortgen F, Boisrame-Helms J, Charpentier J, Guerot E, Megarbane $B$, Grimaldi D, et al. Hyperoxia and hypertonic saline in patients with septic shock (HYPERS2S): a two-by-two factorial, multicentre, randomised, clinical trial. Lancet Respir Med. 2017;5(3):180-90.

4. Damiani E, Adrario E, Girardis M, Romano R, Pelaia P, Singer M, et al. Arterial hyperoxia and mortality in critically ill patients: a systematic review and meta-analysis. Crit Care. 2014;18(6):711.

5. Suzuki S, Eastwood GM, Glassford NJ, Peck L, Young H, Garcia-Alvarez M, et al. Conservative oxygen therapy in mechanically ventilated patients: a pilot before-and-after trial. Crit Care Med. 2014;42(6):1414-22.

6. Panwar R, Hardie M, Bellomo R, Barrot L, Eastwood GM, Young PJ, et al. Conservative versus liberal oxygenation targets for mechanically ventilated patients. A pilot multicenter randomized controlled trial. Am J Respir Crit Care Med. 2016;193(1):43-51.

7. Collins JA, Rudenski A, Gibson J, Howard L, O'Driscoll R. Relating oxygen partial pressure, saturation and content: the haemoglobin-oxygen dissociation curve. Breathe (Sheff). 2015;11(3):194-201.

8. The Acute Respiratory Distress Syndrome Network. Ventilation with lower tidal volumes as compared with traditional tidal volumes for acute lung injury and the acute respiratory distress syndrome. The Acute Respiratory Distress Syndrome Network. N Engl J Med. 2000;342(18):1301-8.

9. de Jonge $E$, Peelen L, Keijzers PJ, Joore $H$, de Lange D, van der Voort PH, et al. Association between administered oxygen, arterial partial oxygen pressure and mortality in mechanically ventilated intensive care unit patients. Crit Care. 2008;12(6):R156.

10. Zhang Z, Ji X. Quadratic function between arterial partial oxygen pressure and mortality risk in sepsis patients: an interaction with simplified acute physiology score. Sci Rep. 2016;6:35133. 
11. Ebmeier SJ, Barker M, Bacon M, Beasley RC, Bellomo R, Knee Chong C, et al. A two centre observational study of simultaneous pulse oximetry and arterial oxygen saturation recordings in intensive care unit patients. Anaesth Intensive Care. 2018;46(3):297-303.

12. Wilson BJ, Cowan HJ, Lord JA, Zuege DJ, Zygun DA. The accuracy of pulse oximetry in emergency department patients with severe sepsis and septic shock: a retrospective cohort study. BMC Emerg Med. 2010;10:9-227X-10-9.

13. Van de Louw A, Cracco C, Cerf C, Harf A, Duvaldestin P, Lemaire F, et al. Accuracy of pulse oximetry in the intensive care unit. Intensive Care Med. 2001;27(10):1606-13.

14. Durlinger EMJ, Spoelstra-de Man AME, Smit B, de Grooth HJ, Girbes ARJ, Oudemans-van Straaten HM, et al. Hyperoxia: at what level of SpO2 is a patient safe? A study in mechanically ventilated ICU patients. J Crit Care. 2017;39:199-204.

15. Helmerhorst HJ, Schultz MJ, van der Voort PH, de Jonge E, van Westerloo DJ. Bench-to-bedside review: the effects of hyperoxia during critical illness. Crit Care. 2015:19:284.

16. Schjørring OL, Toft-Petersen AP, Kusk KH, Mouncey P, Sorensen EE, Berezowicz P, et al. Intensive care doctors' preferences for arterial oxygen tension levels in mechanically ventilated patients. Acta Anaesthesiol Scand. 2018;62(10):1443-51. 